\title{
Next generation sequencing of $R B 1$ gene for the molecular diagnosis of ethnic minority with retinoblastoma in Yunnan
}

\author{
Zhen Zhang ${ }^{1,2 \dagger}$, Yi-shuang Xiao ${ }^{3 \dagger}$, Ru Shen ${ }^{4 \dagger}$, Hong-chao Jiang ${ }^{1}$, Li Tan ${ }^{4}$, Ren-qiu Li ${ }^{4}$, Xiao-hong Yang ${ }^{4}$,
} Huai-yu Gu${ }^{2^{*}}$ D, Wen-Ji He ${ }^{4^{*}}$ and Jing Ma ${ }^{1,5^{*}}$

\begin{abstract}
Background: Retinoblastoma is a rare intraocular malignancy and typically initiated by inactivating biallelic mutations of RB1 gene. Each year, $~ 8000$ children worldwide are diagnosed for retinoblastoma. In high-income countries, patient survival is over $95 \%$ while low-income countries is 30\%.If disease is diagnosed early and treated in centers specializing in retinoblastoma, the survival might exceed $95 \%$ and many eyes could be safely treated and support a lifetime of good vision. In China, approximate 1100 newly diagnosed cases are expected annually and 28 hospitals covering 25 provinces established centers classified by expertise and resources for better treatment options and followup. Comparing with other province of eastern China, Yunnan province is remote geographically. This might result that healthcare staff have low awareness of the role of genetic testing in management and screening in families.

Methods: The patients with retinoblastoma were selected in Yunnan. DNA from blood was used for targeted gene sequencing. Then, an in-house bioinformatics pipeline was done to detect both single nucleotide variants and small insertions/deletions. The pathogenic mutations were identified and further confirmed by conventional methods and cosegregation in families.
\end{abstract}

Results: Using our approach, targeted next generation sequencing was used to detect the mutation of these 12 probands. Bioinformatic predictions showed that nine mutations were found in our study and four were novel pathogenic variants in these nine mutations.

Conclusions: It's the first report to describe RB1 mutations in Yunnan children with retinoblastoma. This study would improve role of genetic testing for management and family screening.

Keywords: Retinoblastoma, Mutations, Targeted next generation sequencing, Genetic forms

\footnotetext{
*Correspondence: 2218458245@qq.com; Hewenji@etyy.cn; Jingma@etyy.cn

†Zhen Zhang, Yi-shuang Xiao and Ru Shen are co-author.

2Department of Human Anatomy, Zhongshan School of Medicine, Sun

Yat-Sen University, Guangzhou, Guangdong 510080, PR China

${ }^{4}$ Kunming Children's Hospital, Kunming Medical University, Kunming, Yunnan 650228 , PR China

'Key Laboratory of Children's Major Disease Research, and Yunnan Institute of Pediatrics, Kunming Children's Hospital, Kunming Medical University, Kunming, Yunnan 650228, PR China

Full list of author information is available at the end of the article
}

(c) The Author(s). 2020 Open Access This article is licensed under a Creative Commons Attribution 4.0 International License, which permits use, sharing, adaptation, distribution and reproduction in any medium or format, as long as you give appropriate credit to the original author(s) and the source, provide a link to the Creative Commons licence, and indicate if changes were made. The images or other third party material in this article are included in the article's Creative Commons licence, unless indicated otherwise in a credit line to the material. If material is not included in the article's Creative Commons licence and your intended use is not permitted by statutory regulation or exceeds the permitted use, you will need to obtain permission directly from the copyright holder. To view a copy of this licence, visit http://creativecommons.org/licenses/by/4.0/ The Creative Commons Public Domain Dedication waiver (http://creativecommons.org/publicdomain/zero/1.0/) applies to the data made available in this article, unless otherwise stated in a credit line to the data. 


\section{Background}

Retinoblastoma (RB, OMIM\#180200) is a rare malignant tumor which rapidly develops from the immature cells of a retina and occurs in infancy or in children, usually before the age of 5 years (about 2/3 children below the age of 2 years, about $95 \%$ children below the age of 5 years) $[1,2]$.

To explain mechanisms of RB, Knudson proposed the famous "two-hit hypothesis". A germline mutation ('first hit', M1) and an acquired somatic mutation ('second hit', M2) arise heritable retinoblastomas; two somatic mutations presented in the same transformation suppressor gene in a susceptible cell, result from non-heritable retinoblastomas [3]. In some patients, Chromosomal deletions pointed to a chromosome (chr.) 13q14 locus. In $70 \%$ of retinoblastoma tumors, the heterozygosity of chr. 13q14 polymorphic loss suggested the second hit involved the same locus [4].

The first cloned gene of tumor suppressor is retinoblastoma $1(R b 1)$ gene. The protein which is encoded by this gene is a cell cycle negative regulator. To maintain the overall chromatin structure, this encoded protein stabilizes constitutive heterochromatin. Defect in $R b 1$ is a cause of childhood cancer $\mathrm{Rb}$, osteogenic sarcoma, and bladder cancer [5].

The gene of $R B 1$ displays a wide spectrum of mutations, including small insertions/deletions (indels), large deletions/duplications, structural variations (SVs), and single nucleotide variations (SNVs) [6-8]. These mutations which are spanning 27 exons are distributed throughout the entire length of the RB1gene. No hotspots have been reported in this gene [9].

The incidence of retinoblastoma is approximately 1 in 16,000-18,000 live births, regardless of sex, race, or geography $[10,11]$. In the United States and Europe, incidence rate of $\mathrm{RB}$ is $2-5$ cases per million children according to WHO [12]. In India, rates of RB incidence are 1.9-12.3 and 1.3-6.7per million in boys and girls, respectively [13]. Dimaras Helen et al. have estimated that approximate 8000 new cases are predicted each year in worldwide [4]. In China, there are about 1100-1500 new cases each year, but only $50 \%$ those children survive [14]. The disease-free survival rate of children with $\mathrm{RB}$ in developed countries is over 95\% [15] while this is substantially lower, at $10-30 \%$ in developing countries $[16,17]$.

Six countries of Asia-Pacific region bear $42.6 \%$ global burden of RB (3452 of 8099 children):1486 children in India (18.3\%), 1103 children in China (13.6\%), 277 children in Indonesia (3.4\%), 260 children in Pakistan (3.2\%), 184 (2.3\%) children in Bangladesh, 142 (1.8\%) children in Philippines [18].

A heritable form and non-heritable form are two forms of the RB disease. Heritable RB accounts for $45 \%$ of all cases which $80 \%$ bilateral, $15 \%$ unilateral and $5 \%$ trilateral. Approximately 55\% of cases are non-heritable $\mathrm{RB}$ that is always unilateral [19]. The mode of RB inheritance is autosomal dominant (AD) found in 10\% of cases.

[20]. The majority of RB patients are sporadic and the only affected members of otherwise unaffected families. The disease is labeled "sporadic" if the family has no history of RB [21].

From presenting signs and clinical examination, diagnosis of RB is usually clear [22]. Leukocoria (white pupil) is the most common sign; Strabismus is the second most common sign when central vision is lost. Due to increased pressure, or non-infective orbital inflammation, advanced disease might present with enlarged cornea and iris colour change $[4,23]$.

The primary goal of management is to save the child's life, followed by salvage of the eye and optimization of visual function. Many treatment options of RB are available and depend on the laterality and extent of RB disease [24]. The various treatment modalities for retinoblastoma includes enucleation of the eye, external beam radiotherapy, brachytherapy, thermotherapy, laser photocoagulation, cryotherapy,systemic chemotherapy, intra-arterial chemotherapy, nanoparticulate chemotherapy and chemoreduction [4]. When children with RB have symptoms, such as leukokoria and strabismus, it is late for these children to have best time for cure. Delayed diagnosis results in incurable invasion of the optic nerve and brain and metastases elsewhere in the body. However, if noticed early, prompt treatment can cure the cancer and save the eye(s) [4]. According to Intraocular International Retinoblastoma Classify (IIRC) which divides retinoblastomas into 5 groups (labeled A through E; Group A means small tumors while group E means large tumor and the eye have no chance to be saved), Children's Hospital of Fudan University reported that about $75 \%$ children with $\mathrm{RB}$ were diagnosed at group D and $\mathrm{E}$ of IIRC when these children saw doctor for the first time [25, 26].

In the management of $\mathrm{RB}$, genetic testing and counseling are extremely important [27]. Heritability form of $R B$ can be identified by genetic testing of the proband [28]. But, genetic testing has not been carried out in Yunnan whose permanent population was $47,368,000$, including $51.48 \%$ male population and $48.52 \%$ female population, $17.79 \%$ children and $62.21 \%$ adults, $66.43 \%$ Han population and $33.57 \%$ minority population according to the $1 \%$ population sample survey by Yunnan Bureau of Statistics (http://stats.yn.gov.cn/).

Therefore, how to carry out genetic testing is an urgent problem in the $\mathrm{RB}$ clinical in developing countries. In this paper, the genes of RB family in Yunnan were studied in order to obtain genetic forms of RB by genetic testing of the probands and then give counseling to 
these families. We use targeted next generation sequencing (NGS) to screen probands and then Sanger sequencing was used to identify variants in other members of pedigrees. In our study, nine mutations were found and four were novel mutations.

\section{Methods \\ Subjects}

The non-consanguineous families from the Yun-Gui Plateau was recruited by the Children's Hospital of Kunming Medical University for genetic diagnosis. In these families, the children suffered from RB, but the parents and other members were normal. This study was approved by the Ethics Committee of the Children's Hospital of Kunming Medical University; in accordance with the principles of the Declaration of Helsinki written informed consent was obtained from the participants or their guardians. The age range of the patients, in which we obtained parental consent, is from 6 to 117 months $(36.50 \pm 38.61)$. In this study, the normal control includes 100 individuals (55 males and 45 females) aged between 5 and 35 years old without associated hereditary diseases.

\section{Clinical evaluations}

All clinical and physical examinations were conducted in the Children's Hospital of Kunming Medical University in Kunming. CT and ultrasound imaging were performed in these probands.

\section{Targeted NGS and variant analysis}

Two-millilitre peripheral blood samples were collected from the probands, siblings and their parents in tubes containing 0.2 M EDTA. Using the QIAamp DNA blood extraction kit (TIANGEN, Beijing, China), DNA was extracted from the venous blood of each subject. According to the manufacturer's protocol (MyGenostics, Inc., Beijing, China), 3 micrograms of genomic DNA was fragmented by Covaris 32, and the 3' end of each DNA fragment was A-tailed. Then, Illumina adapters were ligated to these fragments. We aimed for a 350-400 basepair product, and all samples were checked with Nanodrop 2000 or Qubit systems to determine if they represented a captured library.

Each resulting captured library was loaded on an Illumina MiSeq 2000 sequencing platform, and the sequences were determined to ensure that each sample met the desired average sequencing coverage.

\section{Mutation analysis}

Using Bcl2Fastq software (Bcl2Fastq 2.18.0.12, Illumina, Inc.), raw image files were processed for base calling and raw data generation. In addition, to get a quality score $\geq$ 20, low-quality variations were filtered out. Then, Short
Oligonucleotide Analysis Package (SOAP) aligner software (SOAP2.21, soap.genomics.org.cn/soapsnp.html) was used to align the clean reads to the reference human genome (UCSC hg19, http://genome.ucsc.edu/). Polymerase chain reaction (PCR) duplicates were removed by the Picard programme $[29,30]$.The single nucleotide polymorphisms (SNPs) were determined by the SOAPsnp programme [31]. The reads were realigned by BurrowsWheeler Aligner (BWA) software 0.7.15, and the deletions and insertions (InDels) were detected by Genome Analysis Toolkit software 3.7. In addition, the identified indel SNPs were annotated using the Exome-assistant programme (http://122.228.158.106/exomeassistant). To determine their pathogenicity, non-synonymous variants were evaluated by four algorithms, namely, PolyPhen (http://genetics.bwh.harvard.edu/pph2/), Protein Analysis Through Evolutionary Relationships (PANTHER, www.pantherdb. org), Sorting Intolerant from Tolerant [SIFT, (http://sift. jcvi.org/)] and Pathogenic Mutation Prediction (Pmut; http://mmb.pcb.ub.es/PMut/).

\section{Mutation validation}

PCR and Sanger sequencing with an ABI3500 sequencer were used to confirm potential causative variants in this family. The sites of variation were identified to compare the DNA sequences with the corresponding GenBank (www.ncbi.nlm.nih.gov) reference sequences. The sequences of forward and reverse primers are presented in supplementary Table 1 and were used to confirm potential causative variants in this family.

Thermocycling conditions: An initial denaturation of $95^{\circ} \mathrm{C}$ for $10 \mathrm{~min}, 35$ cycles of denaturation at $94{ }^{\circ} \mathrm{C}$ for $30 \mathrm{~s}$., annealing at $64{ }^{\circ} \mathrm{C}$ for $30 \mathrm{~s}$, extension at $72{ }^{\circ} \mathrm{C}$ for $45 \mathrm{~s}$ and a final extension of $72{ }^{\circ} \mathrm{C}$ for $5 \mathrm{~min}$. The sequences of forward and reverse primers are in supplementary Table 1.

\section{Results \\ Clinical findings}

Twelve patients with RB were selected for this study of targeted RB1 sequencing from non-consanguineous Yunnan families. There are no pathogenic or likely pathogenic variants were detected in three probands with our approach while nine variants in nine families.

\section{The clinical findings of probands}

In these nine families,there are seven boys and two girls (See Fig. 1). Minority nationalities have Dai, Hani, Bai, Hui, Yi and Han. Mean age at diagnosis is $23 \pm 9.9$ months for unilateral and $11 \pm 8.5$ months for bilateral retinoblastoma in our study, respectively. Six probands were diagnosed with bilateral $\mathrm{RB}$ while three with the unilateral form. There are common sign leukocoria in probands of families 1, 3, 4, 6, 7; in family 2, left eye of 


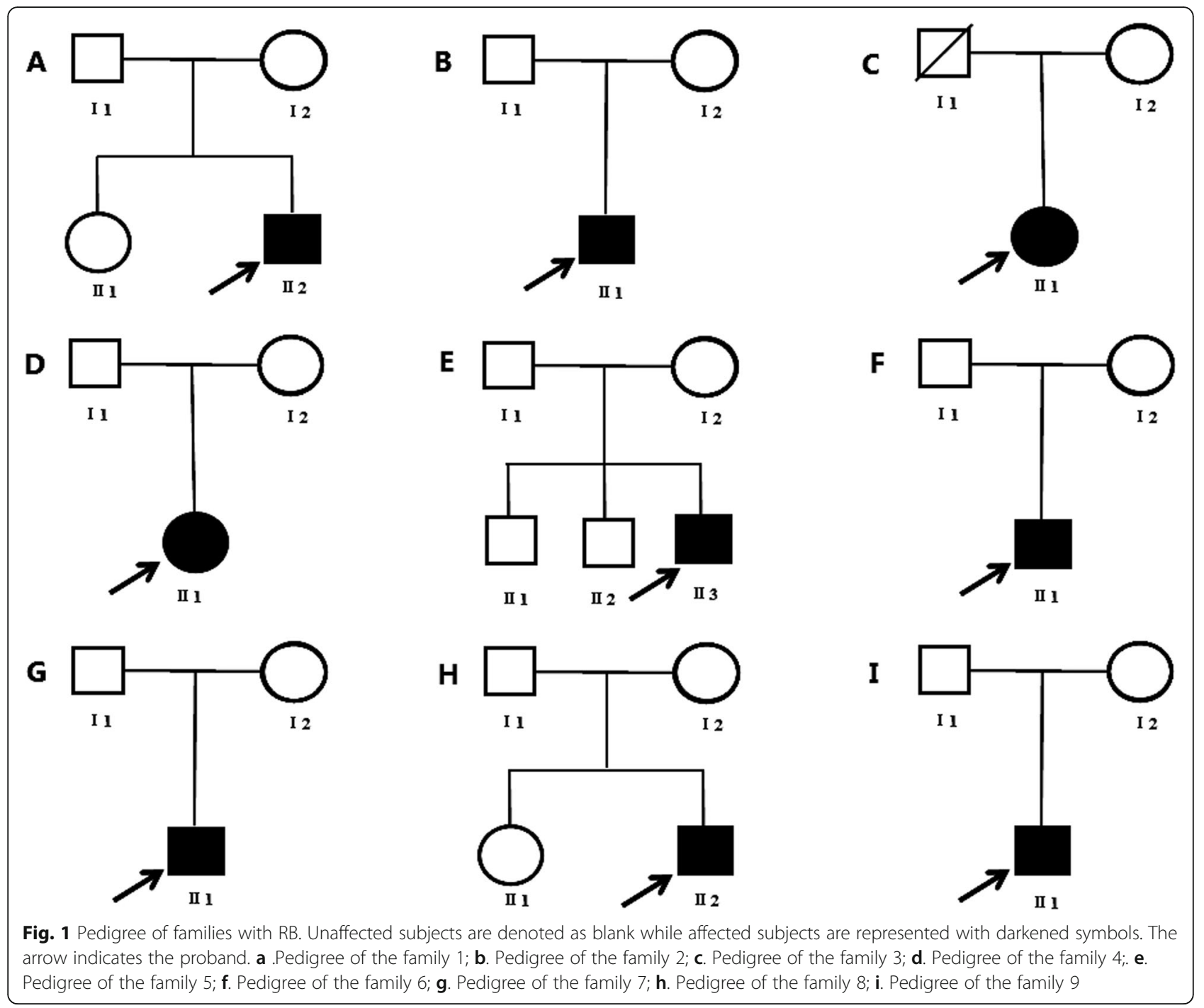

Table 1 Clinical features of patients with RB

\begin{tabular}{|c|c|c|c|c|c|c|c|}
\hline \multirow[t]{2}{*}{ Patient } & \multirow[t]{2}{*}{ Sex } & \multirow{2}{*}{$\begin{array}{l}\text { Minority } \\
\text { Nationalities }\end{array}$} & \multirow{2}{*}{$\begin{array}{l}\text { Age } \\
\text { (Months) }\end{array}$} & \multicolumn{2}{|c|}{ Onset Age (Months) } & \multicolumn{2}{|c|}{ Fundus Appearance } \\
\hline & & & & $\overline{\mathrm{LE}}$ & RE & $\overline{\mathrm{LE}}$ & RE \\
\hline 1 & M & Dai & 12 & 6 & 6 & $\mathrm{RB}$ & $\mathrm{RB}$ \\
\hline 2 & M & Hani & 106 & $14^{a}$ & 17 & - & $\mathrm{RB}$ \\
\hline 3 & $\mathrm{~F}$ & Bai & 12 & 9 & - & $\mathrm{RB}$ & - \\
\hline 4 & $\mathrm{~F}$ & Han & 18 & 13 & 13 & $\mathrm{RB}$ & $\mathrm{RB}$ \\
\hline 5 & M & Hui & 28 & 26 & 26 & $\mathrm{RB}$ & $\mathrm{RB}$ \\
\hline 6 & M & Yi & 11 & 6 & - & $\mathrm{RB}$ & - \\
\hline 7 & M & Hani & 60 & 54 & - & $\mathrm{RB}$ & - \\
\hline 8 & M & Han & 6 & 5 & 5 & $\mathrm{RB}$ & $\mathrm{RB}$ \\
\hline 9 & M & Han & 10 & 3 & 3 & $\mathrm{RB}$ & $\mathrm{RB}$ \\
\hline
\end{tabular}

Abbreviations: $M$ Male, LE Left eye, RE Right eye, Retinoblastoma (RB);The children of these families exhibited similar clinical features of RB. Ophthalmic examinations showed that the child in these families are affected by RB. ${ }^{\text {a }}$ Removed at 15 months 
the proband had been removed; the proband of 5 had strange reflection; the proband had blurred vision and shed tears in 8 and 9 (Table 1).

\section{The clinical findings of parents}

There was no congestion in the conjunctiva, no secretions in the conjunctival sac., and no tumor in both eyes. In both eyes (OU), the microscopy of slit lamp showed that the cornea is smooth and transparent, the thickness of corneal is normal, the depth of anterior chamber is normal, cornea is clear, iris texture is clear, pupil is isometric, lens is transparent, interstitial is clear and light emission exists.

\section{Targeted NGS}

The mean read depth of coverage for each proband sample ranged from 52 to $66 \mathrm{X}$, and the average throughput depth of the target region in each sample ranged from 90 to 99X. NGS produced reads from 32.8 to 56.12 million reads and the read length from 148 to $149 \mathrm{bp}$. The reads aligned to the human genome and mapped to the target region with a mean coverage from 99.8 to $99.9 \%$. The SNPs and Indels are reported in supplementary Table 2.

\section{Identification of SNVs and InDels in children with RB patients}

To detect SNVs and InDels, we analyzed blood samples of 6 bilateral patients and 3 familial unilateral patient and identified pathogenic variants in 8 patients and likely pathogenic variants in 1 patient. Four were novel and five were previously reported (Table 2). The spectrum of identified mutations includes 5 SNVs (1 nonsynonymous and 4 stop gain), one deletion (1 frameshift), and 3 splice site variants (splice).

Eight of them were shown to be de novo, and remaining one was inherited from one of their mothers.

\section{Identification of pathogenic mutation}

Sanger sequencing and cosegregation further confirmed all the pathogenic variants (See Figs. 2 and 3). We detected 9 mutations which 4 were novel and 5 were known (Table 2). Additionally, these four novel mutations were absent in 100 normal control individuals.

\section{Discussion}

$\mathrm{RB}$ is the most common intraocular malignancy in childhood and presents in one or both eyes. Through presenting signs and clinical examination, diagnosis of RB is usually clear [22]. In our study, five probands had leukocoria; one proband had strange reflection; one proband's left eye was enucleated; two had blurred vision. Mean age at diagnosis was $23 \pm 9.9$ months for unilateral and $11 \pm 8.5$ months for bilateral. According to Gene Reviews and AlAli et al. (Mean ageat diagnosis is 24 months for unilateral and 15 months for bilateral; mean age at diagnosis to be 27 months for unilateral and 15 months for bilateral, respectively), our mean age at diagnosis is not later than elsewhere in the world [24]. However, there no tumor in parents of these families.. And especially in family 3 and 7, the visions of the parents were normal.

Genetic testing of $R B 1$ is beneficial to provide counselling for families. In patients with $R B$, identification of gene alterations improves clinical management of patient and relatives at risk [32]. Here, we have used targeted NGS approach for the molecular analysis of Yunnan Children with $\mathrm{RB}$, based on targeted gene enrichment and bioinformatics pipeline. We used in-house pipeline to successfully detect both pathogenic variants in RB patients. The average throughput depth of the target region in each sample ranged from 90-99X. These met the desired average sequencing coverage which was ensured to provide high quality bases for sensitive and efficient variant detection. To detect SNVs and InDels for all the samples, we developed an automatic in-house variant calling pipeline as freely available tools. The pathogenic SNVs and InDels were identified by stringent criteria,

Table 2 Variants identified by NGS in blood samples of RB chidren

\begin{tabular}{|c|c|c|c|c|c|c|c|c|}
\hline No. & $\begin{array}{l}\text { Locations on the } \\
\text { chromosomes }\end{array}$ & Exon & Mutation & & $\begin{array}{l}\text { Pathogenic } \\
\text { analysis }\end{array}$ & Allele & Protein & $\begin{array}{l}\text { Cosegregation in } \\
\text { family }\end{array}$ \\
\hline 1 & chr13-48,942,673-48,942,675 & 11 & c.1061_1062del & novel & pathogenic & het & p.R355Nfs*6 & De novo \\
\hline 2 & chr13-49,030,485 & 19 & c. $1960 \mathrm{G}>\mathrm{C}$ & known & Likely pathogenic & het & p.V654L & De novo \\
\hline 3 & chr13-49,039,158 & 22 & c. $2236 \mathrm{G}>\mathrm{T}$ & novel & pathogenic & het & p.E746X & Heterozygous mother \\
\hline 4 & chr13-49,047,526-49,047,530 & 24 & c. $2520+1 \_2520+4$ delGTGA & novel & pathogenic & het & splicing & De novo \\
\hline 5 & chr13-48,955,538 & 17 & c. 1654 C > T & known & Pathogenic & het & p.R552X & De novo \\
\hline 6 & chr13-49,027,168 & 18 & c.1735 C > T & known & pathogenic & het & p.R579x & De novo \\
\hline 7 & chr13-48,881,547 & 2 & $c .264+5 G>A$ & novel & pathogenic & het & splicing & De novo \\
\hline 8 & chr13-48,942,685 & 11 & c. $1072 C>T$ & known & pathogenic & het & p.R358X & De novo \\
\hline 9 & chr13-48,923,160 & 6 & $c .607+1 G>A$ & known & pathogenic & het & splicing & De novo \\
\hline
\end{tabular}




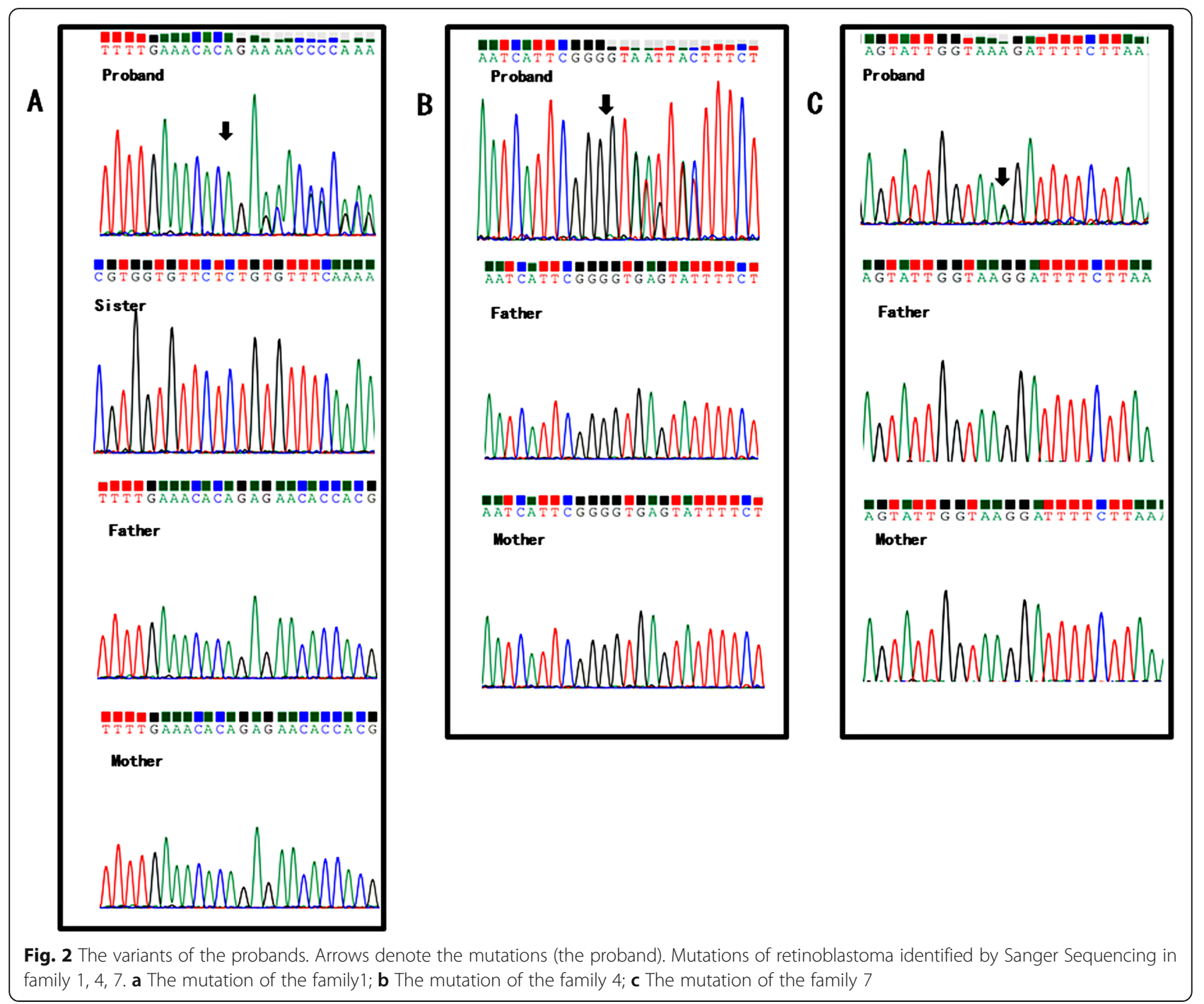

and 8 the pathogenic and 1 likely pathogenic variants were further confirmed by conventional methods and cosegregation with phenotype. Targeted mutation analysis is useful to study mutations in blood and can detect DNA variations. The RB1 gene of seven families' member are normal and only in family 3and 7, the unaffected mother of this family are heterozygous and the same to the proband. Seven proband's genes are spontaneous mutation. Four mutations were newly discovered mutations and never reported before. With genetic testing, mutation profiles might be created to precisely screen mutations of relatives or subsequent generations in these families. Four families' other children had no mutations by gene testing while other five families are one-child family.

However, no RB1 mutations were found in the remaining $25 \%$ (3/12) of cases. This could be due to the fact that there are the weakness of study, like not doing cytogenetic studies such as chromosomal microarray
(Identification of chromosome translocations or large gross deletions) and multiplex ligation-dependent probe amplification assays (MLPA identifies deletions or rearrangements of 1 or several exons, which account for $16 \%$ of all aberrations in RB1). This possibly results in 3 unsolved cases. The combined and cost-effective approach, such as method using a combination of direct sequencing and MLPA, were needed to accurately detect this 3 "negative cases" in next study.

Clearly, study of social determinants of health, such as health seeking behavior, perceptions of medical care, and sociocultural issues related to cancer inheritance would inform counselling approaches that meet the needs of families [33]. This study is helpful for the molecular diagnosis of $\mathrm{RB}$ in a comprehensive in Yunnan. These might provide molecular diagnosis to doctor for RB management because lack of genetic testing counseling, poor access to multidisciplinary retinoblastoma-specific health care and socioeconomic 


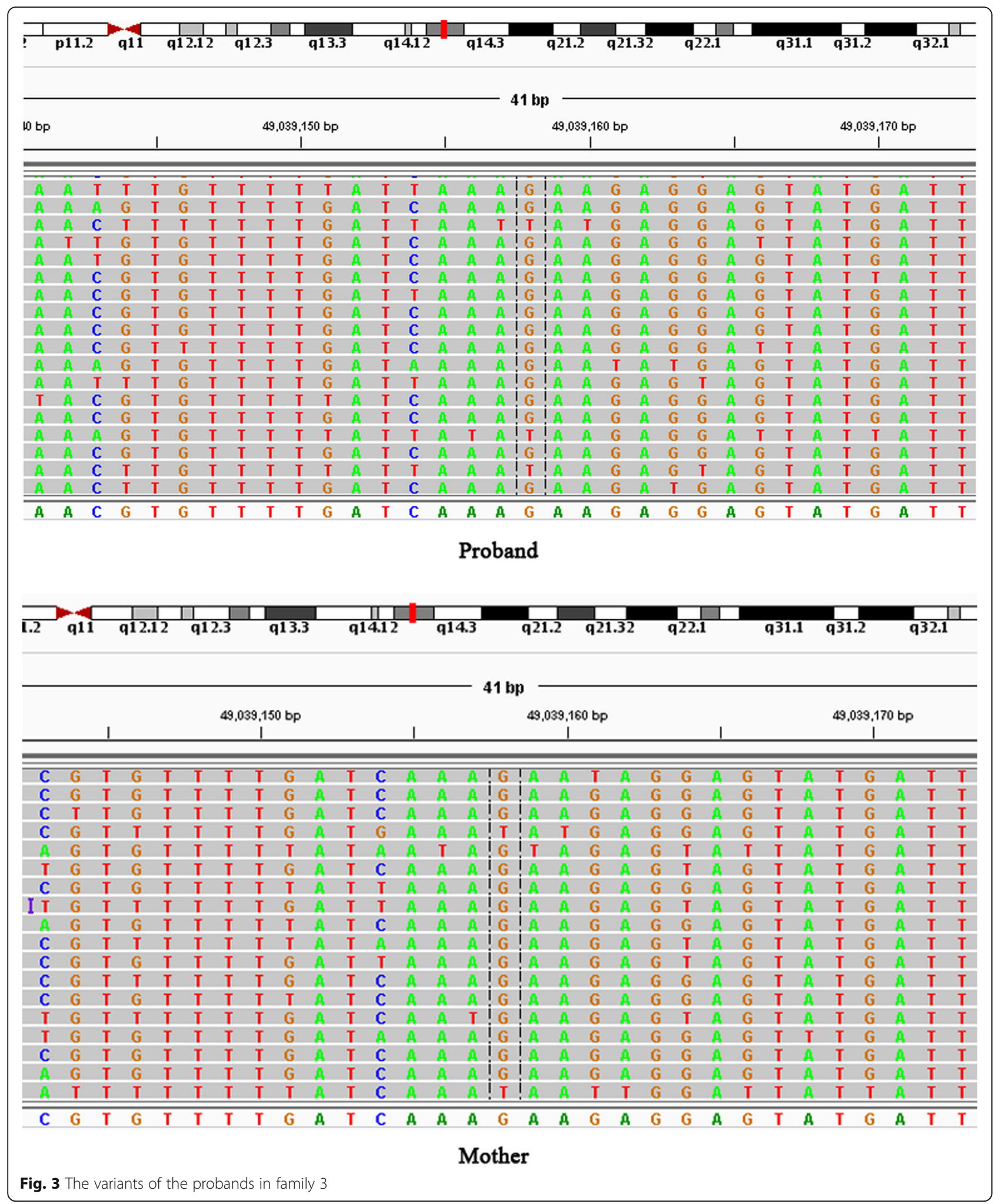

factors are one of the factors of higher mortality globally. For the probands with germlinemutation, the molecular diagnosis also provides counseling because the later life of patients with heritable RB displayed that these patients have a high life $\neg$ time risk of developing second primary malignancies, such as osteosarcomas, melanomas and soft-tissue sarcomas [34-36]. 
However, in this cohort, the small number of patients is not enough to establish a significant frequency reference and functional studies are necessary for assigning pathogenicity to these novel variants.

\section{Conclusion}

Here, we reported that this approach with bioinformatics pipeline could detect variants including novel pathogenic variants. This comprehensive approach reduces the time and number of assays required for the detection of pathogenic variants by conventional methods. To the best of our knowledge, this is the first such study using targeted NGS approach to detect pathogenic variants in Yunnan children with RB. Overall, targeted NGS approach is becoming more feasible in clinical settings.

\section{Supplementary Information}

The online version contains supplementary material available at https://doi. org/10.1186/s12881-020-01150-7.

Additional file 1: Supplementary Table 1.PCR primers for amplification. Supplementary Table 2. Coverage level through the target region for patients.

\section{Abbreviations}

RB: Retinoblastoma; IIRC: Intraocular International Retinoblastoma Classify; NGS: Next generation sequencing; SOAP: Short Oligonucleotide Analysis Package; PCR: Polymerase chain reaction; SNPs: Single nucleotide polymorphisms; BWA: Burrows-Wheeler Aligner; InDels: Deletions and insertions; SIFT: Sorting Intolerant from Tolerant; SNVs: Single nucleotide variants

\section{Acknowledgements}

We thank all subjects who participated in this study.

\section{Authors' contributions}

$Z Z, Y S X, W J H$ and R S conceived and designed the experiments; Z Z, R S, W J H, HC J, L T, R Q Land J M performed the experiments; Z Z, Y S X, J M, H C J, X H Y, W J H and L T analyzed the data; Y S X, R Q Land W J H recruited patients and collected clinical information.. YS X, R Q L,R S, H C J, and $H Y G$ contributed to accumulation and interpretation of clinical data. W $\mathrm{J} H, J M H Y G$ and $Z \mathrm{Z}$ coordinated the project. All authors read and approved the final manuscript.

\section{Funding}

This work was supported by a grant from the Joint Fund of the Yunnan Science and Technology Department and Kunming Medical-University [grants nos. 2019FE001(-274)], the Health and Family Planning Commission of Kunming and Yunnan [grants nos. 2017-SW (Yang)-02 and H-2018012], Key R \& D plan of Yunnan Provincial Department of science and technology----International cooperation in science and technology (grants nos. 2018IA047), Cultivation of Reserve Talents for Young and Middle-aged Academic and Technical Leaders of Yunnan Province (2019HB102), and Innovation team of Yunnan Province for comprehensive Prevention and Treatment of Children's hearing impairment and language diseases (2019HC026), respectively. The funding bodies played no role in the design of the study and collection, analysis, and interpretation of data and in writing the manuscript.

\section{Availability of data and materials}

The raw sequencing data of NGS are available in the NCBI's Sequence Read Archive (SRA) with accession number PRJNA666751 (SRR12762344, SRR12762345, SRR12762346, SRR12762347) https://dataview.ncbi.nlm.nih.gov/ object/PRJNA666751? reviewer=mlmsrbpj2u60r1ss0ijmkgmole". The other data and materials are available from the corresponding author (JM) or first author (ZZ) upon reasonable request.

\section{Ethics approval and consent to participate}

This study was approved by the ethics committee of Kunming Children's Hospital, Kunming Medical University. Written informed consents were obtained from all participants in this study. Moreover, written informed consents were obtained from the parents of all participants under the age of 16. The ethics committee of Kunming Children's Hospital, Kunming Medical University, were acquired by our team to access the data we used in our research.

\section{Consent for publication}

All participants have provided written informed consents to publish all identifying images, personal details and clinical details anonymously. Moreover, written informed consent for publication of identifying images or other personal or clinical details was obtained from the parents of any participant under the age of 18 .

\section{Competing interests}

The authors declare that they have no competing interests.

\section{Author details}

${ }^{1}$ Key Laboratory of Children's Major Disease Research, and Yunnan Institute of Pediatrics, Kunming Children's Hospital, Kunming Medical University, Kunming, Yunnan 650228, PR China. '2Department of Human Anatomy, Zhongshan School of Medicine, Sun Yat-Sen University, Guangzhou, Guangdong 510080, PR China. ${ }^{3}$ Department of Ophthalmology, Kunming Children's Hospital, Kunming Medical University, Kunming, Yunnan 650228, PR China. ${ }^{4}$ Kunming Children's Hospital, Kunming Medical University, Kunming, Yunnan 650228, PR China. ${ }^{5}$ Department of Otolaryngology-Head Neck Surgery, Kunming Children's Hospital, Kunming Medical University" Kunming, Yunnan 650228, PR China.

Received: 19 January 2020 Accepted: 15 October 2020

Published online: 23 November 2020

References

1. Bornfeld N, Biewald E, Bauer S, Temming P, Lohmann D, Zeschnigk M. The interdisciplinary diagnosis and treatment of intraocular tumors. Dtsch Arztebl Int. 2018;115(7):106-11.

2. Dimaras $H$, Khetan V, Halliday W, Orlic M, Prigoda NL, Piovesan B, Marrano $P$ Corson TW, Eagle RJ, Squire JA, et al. Loss of RB1 induces non-proliferative retinoma: increasing genomic instability correlates with progression to retinoblastoma. Hum Mol Genet. 2008;17(10):1363-72.

3. Comings DE. A general theory of carcinogenesis. Proc Natl Acad Sci U S A 1973;70(12):3324-8.

4. Dimaras H, Corson TW, Cobrinik D, White A, Zhao J, Munier FL, Abramson DH, Shields CL, Chantada GL, Njuguna F, et al. Retinoblastoma. Nat Rev Dis Primers. 2015;1(1):15021..

5. Lohmann D. Retinoblastoma. Adv Exp Med Biol. 2010;685:220-7.

6. Valverde JR, Alonso J, Palacios I, Pestana A. RB1 gene mutation up-date, a meta-analysis based on 932 reported mutations available in a searchable database. BMC Genet. 2005;6:53.

7. Devarajan B, Prakash L, Kannan TR, Abraham AA, Kim U, Muthukkaruppan V, Vanniarajan A. Targeted next generation sequencing of RB1 gene for the molecular diagnosis of retinoblastoma. BMC Cancer. 2015;15:320.

8. Lohmann DR. RB1 gene mutations in retinoblastoma. Hum Mutat. 1999; 14(4):283-8

9. Jaya Singh AMAJ. Next-generation sequencing-based method shows increased mutation detection sensitivity in an Indian retinoblastoma cohort. Mol Vis. 2016;22:1036-47.

10. Kivela T. The epidemiological challenge of the most frequent eye cancer: retinoblastoma, an issue of birth and death. Br J Ophthalmol. 2009;93(9): 1129-31.

11. Broaddus $E$, Topham A, Singh AD. Incidence of retinoblastoma in the USA 1975-2004. Br J Ophthalmol. 2009;93(1):21-3.

12. Retinoblastoma union for International Cancer Control WHO.2014.

13. Satyanarayana L, Asthana S, Labani SP. Childhood cancer incidence in India: a review of population-based cancer registries. Indian Pediatr. 2014;51(3): 218-20. 
14. Song Z. Effect and mechanism of silencing SHH gene on the proliferation and apoptosis of retinoblastoma cell: Jilin University; 2016.

15. Canadian Retinoblastoma Society. National Retinoblastoma Strategy Canadian Guidelines for Care: Strategie therapeutique du retinoblastome guide clinique canadien. Can J Ophthalmol. 2009;44(Suppl 2):S1-S88.

16. Canturk S, Qaddoumi I, Khetan V, Ma Z, Furmanchuk A, Antoneli CB, Sultan I, Kebudi R, Sharma T, Rodriguez-Galindo C, et al. Survival of retinoblastoma in less-developed countries impact of socioeconomic and health-related indicators. Br J Ophthalmol. 2010;94(11):1432-6.

17. Dean M, Bendfeldt G, Lou H, Giron V, Garrido C, Valverde P, Barnoya M, Castellanos M, Jimenez-Morales S, Luna-Fineman S. Increased incidence and disparity of diagnosis of retinoblastoma patients in Guatemala. Cancer Lett. 2014;351(1):59-63.

18. Jain M, Rojanaporn D, Chawla B, Sundar G, Gopal L, Khetan V. Retinoblastoma in Asia. Eye (Lond). 2019:33(1):87-96.

19. Soliman SE, Racher H, Zhang C, MacDonald H, Gallie BL. Genetics and molecular diagnostics in retinoblastoma--an update. Asia Pac J Ophthalmol (Phila). 2017;6(2):197-207.

20. Vogel F. Genetics of retinoblastoma. Hum Genet. 1979;52(1):1-54.

21. Yun J, Li Y, Xu CT, Pan BR. Epidemiology and Rb1 gene of retinoblastoma. Int J Ophthalmol. 2011;4(1):103-9.

22. Dimaras H, Kimani K, Dimba EA, Gronsdahl P, White A, Chan HS, Gallie BL. Retinoblastoma. Lancet. 2012;379(9824):1436-46.

23. Dimaras H. Retinoblastoma genetics in India: from research to implementation. Indian J Ophthalmol. 2015;63(3):219-26.

24. AlAli A, Kletke S, Gallie B, Lam WC. Retinoblastoma for pediatric ophthalmologists. Asia Pac J Ophthalmol (Phila). 2018;7(3):160-8..

25. Linn MA. Intraocular retinoblastoma: the case for a new group classification. Ophthalmol Clin N Am. 2005;18(1):41-53.

26. Gao YJ, Qian J, Yue H, Yuan YF, Xue K, Yao YQ. Clinical characteristics and treatment outcome of children with intraocular retinoblastoma: a report from a Chinese cooperative group. Pediatr Blood Cancer. 2011;57(7):1113-6.

27. Skalet AH, Gombos DS, Gallie BL, Kim JW, Shields CL, Marr BP, Plon SE, Chevez-Barrios P. Screening children at risk for retinoblastoma: consensus report from the American Association of Ophthalmic Oncologists and Pathologists. Ophthalmology. 2018;125(3):453-8.

28. Roelofs K, Shaikh F, Astle W, Gallie BL, Soliman SE. Incidental neuroblastoma with bilateral retinoblastoma: what are the chances? Ophthalmic Genet. 2018;39(3):410-3.

29. Etherington GJ, Ramirez-Gonzalez RH, MacLean D. bio-samtools 2: a package for analysis and visualization of sequence and alignment data with SAMtools in ruby. Bioinformatics. 2015;31(15):2565-7.

30. Li H, Handsaker B, Wysoker A, Fennell T, Ruan J, Homer N, Marth G, Abecasis $G$, Durbin R. The sequence alignment/map format and SAMtools. Bioinformatics. 2009;25(16):2078-9.

31. Li R, Yu C, Li Y, Lam TW, Yiu SM, Kristiansen K, Wang J. SOAP2: an improved ultrafast tool for short read alignment. Bioinformatics. 2009;25(15):1966-7.

32. Richter S, Vandezande K, Chen N, Zhang K, Sutherland J, Anderson J, Han L, Panton R, Branco P, Gallie B. Sensitive and efficient detection of RB1 gene mutations enhances Care for Families with retinoblastoma. Am J Hum Genet. 2003;72(2):253-69.

33. He LQ, Njambi L, Nyamori JM, Nyenze EM, Kimani K, Matende I, Rono H, Njom V, Bett J, Mukuria M, et al. Developing clinical cancer genetics services in resource-limited countries: the case of retinoblastoma in Kenya. Public Health Genom. 2014;17(4):221-7.

34. Kleinerman RA, Tucker MA, Abramson DH, Seddon JM, Tarone RE, Fraumeni $\mathrm{JJ}$. Risk of soft tissue sarcomas by individual subtype in survivors of hereditary retinoblastoma. J Natl Cancer Inst. 2007;99(1):24-31.

35. Kleinerman RA, Yu CL, Little MP, Li Y, Abramson D, Seddon J, Tucker MA Variation of second cancer risk by family history of retinoblastoma among long-term survivors. J Clin Oncol. 2012;30(9):950-7.

36. MacCarthy A, Bayne AM, Brownbill PA, Bunch KJ, Diggens NL, Draper GJ, Hawkins MM, Jenkinson HC, Kingston JE, Stiller CA, et al. Second and subsequent tumours among 1927 retinoblastoma patients diagnosed in Britain 1951-2004. Br J Cancer. 2013;108(12):2455-63.

\section{Publisher's Note}

Springer Nature remains neutral with regard to jurisdictional claims in published maps and institutional affiliations.

\section{Ready to submit your research? Choose BMC and benefit from:}

- fast, convenient online submission

- thorough peer review by experienced researchers in your field

- rapid publication on acceptance

- support for research data, including large and complex data types

- gold Open Access which fosters wider collaboration and increased citations

- maximum visibility for your research: over $100 \mathrm{M}$ website views per year

At BMC, research is always in progress.

Learn more biomedcentral.com/submissions 